\title{
Educación Move Commons. \\ Procomún, Cultura Libre y acción colaborativa desde una pedagogía crítica, mediática y e-visual
}

\author{
Move Commons Education. \\ Commons, Free Culture and collaborative action from a critical, media \\ and e-visual pedagogy
}

\author{
Carlos Escaño \\ Facultad de Educación. Universidad de Sevilla. \\ jcescano@us.es
}

Recibido: 3 de mayo de 2012

Aprobado: 11 de septiembre de 2012

\section{Resumen}

La cultura es un procomún. Esta idea es una premisa para el desarrollo educativo. Aunque como proposición inicial debe ser justificada para que, en consecuencia, podamos asumir una defensa, recreación y difusión de la propia cultura de manera compartida por toda la ciudadanía. Todo bien colectivo nos obliga a desarrollarlo e implementarlo.

Como fuente de conocimiento compartido, la cultura está vinculada a la educación desde un punto de vista histórico y completamente legítimo, y en consecuencia, ineludiblemente, emerge el desarrollo del compromiso con la idea de procomún. En este sentido podríamos establecer un acercamiento a las iniciativas move commons que servirían para (re)nombrar la actividad educativa que se caracteriza en esencia por la acción colaborativa, abierta y vinculada al desarrollo de los comunes.

Para acometer un análisis holístico y amplio de las relaciones entre cultura libre y educación se establecen varias líneas de acción: la pedagogía crítica, la educación mediática y una educación artística-cultural-visual adaptada a nuestros actuales contextos digitalizados (que podríamos denominar pedagogía e-visual).

Palabras clave: Move Commons, procomún, cultura libre, pedagogía crítica, educación mediática, educación e-visual.

Escaño, C. (2013): Educación Move Commons. Procomún, Cultura Libre y acción colaborativa desde una pedagogía crítica, mediática y e-visual. Arte, Individuo y Sociedad, 25(2) 319-336 


\begin{abstract}
Culture is a commons. This idea is a prerequisite for educational development. Although as initial proposal must be justified so that therefore we can assume a defense, recreation and disseminating of own culture shared by all citizens. All common good requires us to develop it and deploy it.

As a source of shared knowledge, culture is linked to education from a historical point of view and completely legitimate, and therefore inevitably the development of commitment to the idea of commons emerges. In this sense we could establish an approach to move commons initiatives that serve to (re) name the educational activity which is characterized essentially by the action collaborative, open and linked to the development of the commons.

To undertake a holistic and comprehensive analysis of the relationship between free culture and education are proposed several lines of action: critical pedagogy, media education and art-cultural-visual education, which is adapted to our current digitized contexts (we might call e-visual pedagogy).
\end{abstract}

Key Words: Move Commons, commons, free culture, critical pedagogy, media education, e-visual.

Escaño, C. (2013): Move Commons Education. Commons, Free Culture and collaborative action from a critical, media and e-visual pedagogy. Arte, Individuo y Sociedad, 25(2) 319-336

Sumario: 1. Introducción, 2. Procomún y Cultura, 2.1. Aproximación a los bienes de provecho común (procomún), 2.2. Estimulación cognitiva y aprendizaje, 3. Relaciones del procomún cultural y la educación, 3.1. Educación y cultura digital (como bien público artificial), 4.Una educación 'move commons' desde la pedagogía crítica, estética y mediática, 4.1. Perspectivas críticas (mediáticas y estéticas) desde contextos contemporáneos, 5. Conclusiones (o ‘sinclusiones'). Referencias.

\title{
1. Introducción
}

"Poblad con igualdad el territorio, estableced idénticos derechos, llevad por todas partes la abundancia y la vida, y el Estado llegará a ser el más fuerte a la vez que el mejor gobernado que sea posible" (Rousseau, 2004, p.158).

La dimensión educativa ha asumido históricamente el reto de desarrollar la cultura, la cual se traduce asimismo como un hecho compartido por toda la ciudadanía. Un hecho colectivo que por definición se traduce en procomún, obligándonos en consecuencia a desarrollarlo, implementarlo y protegerlo entre todos y entre todas. El desarrollo cultural, en consecuencia, necesita de una acción plural y mulidisciplinar para ser atendido de manera óptima desde la esfera educativa: una propuesta educativa -"move commons"- desde la colectividad, que aúna aquella educación artística que ha asumido su papel contemporáneo con coherencia, aliada con una educación mediática más una oportuna pedagogía crítica como aglutinante.

\section{Procomún y Cultura}

\subsection{Aproximación a los bienes de provecho común (procomún)}

"El procomún es un tipo particular de ordenación institucional para gobernar el uso y la disposición de los recursos. Su característica prominente, que la define en contraposición a la propiedad, es que ninguna persona individual tiene un control exclusivo sobre el uso y la disposición de cualquier recurso particular. En cambio, los recursos gobernados por procomún pueden ser usados por, o estar a disposición de, cualquiera que forme parte de 
un cierto número de personas (más o menos bien definido), bajo unas reglas que pueden abarcar desde «todo vale» a reglas formales finamente articuladas y cuyo respeto se impone con efectividad" (Benkler, 2003, p.2).

Benkler nos ofrece una visión muy clara sobre el concepto de procomún, y siguiendo el pensamiento de Antonio Lafuente, podemos decir que, en definitiva, la intención es actualizar una idea ya clásica, recuperarla para nuestros contextos contemporáneos: reivindicar el procomún es reivindicar la existencia de bienes que son comunes a todos, de bienes que pertenecen a cada miembro de la ciudadanía, y que como tales deben ser activamente protegidos; el procomún se traduce en aquellas cosas que heredamos y creamos conjuntamente y que finalmente esperamos legar a las siguientes generaciones (Lafuente, 2007).

Los bienes de provecho común (de ahí el término procomún) hunden históricamente sus principales raíces conceptuales -dentro de nuestra cultura occidental- en las tesis platónicas que se establecen en la obra La República, donde se aboga por una educación común completa, es decir, vinculante al conjunto social en relación a su decisión y control. Aristóteles discutió rigurosa y abiertamente ciertos planteamientos platónicos sobre la comunidad, pero en ningún momento niega la necesidad de que los miembros de la ciudadanía mantengan una seria responsabilidad compartida en la consecución del provecho común. Un buen ejemplo se observa cuando Aristóteles expone en relación con el territorio o las necesidades alimenticias que:

"Los asociados deben tener necesariamente un punto de unidad común, ya sean, por otra parte, en razón de su participación en ella iguales o desiguales: por ejemplo, los alimentos, la posesión del suelo o cualquier otro objeto semejante" (Aristóteles, s.f. p.62).

Posterior al momento cultural de la Antigüedad Clásica (incluyendo las visiones romanas de Cicerón y Séneca), y a lo largo de los subsiguientes siglos hasta llegar a la modernidad, el concepto de lo común ha sido elemento clave para la optimización social: como muestra manifiesta, Sto. Tomás de Aquino utiliza la noción de bonun commune como criterio regulador de justicia social, o Nicolás Maquiavelo, que incluso justifica los medios -a priori- injustos para lograr ese fin y bien común.

En todos estos casos como explica Martínez Gómez, el "bien común" es superior a la suma de los bienes particulares de los individuos que los componen, de ahí que éstos deban estar subordinados siendo el Estado el garante de la subordinación (Martínez, 2011). No obstante, a partir del momento histórico moderno existe un cambio de rumbo:

"Así las revoluciones modernas concebidas como proyectos encaminados al logro de un ideal de sociedad en el que el bienestar general hiciera posible a su vez el bienestar individual. En este contexto, el bien común se ordena en función del bien de los individuos particulares, considerando que no puede existir sin el bien de las personas individuales (...) A partir de la filosofía moderna y, en concreto, del liberalismo político que se inició con el empirismo inglés, el concepto de bien común pasó a ser tratado en función de aspectos económicos fundados en el derecho "natural" a la propiedad privada; fue entonces que se comenzó a hablar preferentemente de "interés general", noción más ligada al contexto 
socioeconómico de la época que la de bien común, que tiene un sentido mucho más ético y metafísico" (Martínez Gómez, 2011, 10).

Marx y Engels advirtieron que el interés general preconizado desde las tesis liberales escondía el interés común de aquellos que dominaban la sociedad. Una dominación vinculada al poder económico.

Era de esperar que tras el desarrollo de las democracias modernas y representativas, ese poder se distribuyera realmente en la ciudadanía, pero como el propio Martínez Gómez aclara:

"La realidad de los acontecimientos vendría a darle la razón a Rousseau cuando planteó que en las democracias representativas no existe tal poder del pueblo, porque al ser mediatizado comienza a ser directamente el poder de quienes le representan" $(2011,21)$.

La crisis actual ha puesto de relieve una idea que ya nos es muy familiar: la ciudadanía no es quien gobierna, gestiona y desarrolla el bien común. Lo explicamos con hechos evidentes: en el momento que una banca privada debe ser "rescatada" por un dinero público-común por el simple hecho de que sin esa banca el estadonación podría desmoronarse, estamos ante la confirmación de una subyugación de poderes. En el momento en el que un estado-nación debe ser "rescatado" (Irlanda, Portugal o Grecia), su descomunal nivel de endeudamiento (incluyendo los altos intereses) hace que ese estado nación visibilice su verdadera forma de gobierno: de la democracia representativa a la deudocracia más hiriente. ${ }^{1}$ En pocos años los ciudadanos nos hemos acostumbrados a que sea el mercado y sus titiriteros (Goldman Sachs, Moody's o Standard \& Poor's) quienes dicten las líneas político-económicas que los estados deben asumir (acatar) para dar viabilidad a sus proyectos económicos.

Actualmente el sentido que cobra la defensa de los comunes, del procomún, es un posicionamiento claro ante los intereses privados que, directamente, se traducen hoy como económicos, pasando de ser privados a únicos y exclusivos por parte de una plutocracia. La defensa del procomún es una reivindicación de independencia ante los poderes mercantilistas, un modo legítimo de expresar que no todo debe y puede ser extrapolado a un mercado de valores (económicos). De manera curiosa, aquella defensa de las libertades, propia de las tesis liberales ahora está en peligro de extinción dentro de nuestros contextos inmersos bajo la dominación oligarca y mercantilista. A la luz de los acontecimientos podría interpretarse que bajo la solicitud del derecho de libre pensamiento y expresión se escondiera un único interés: un interés desmedido por la propiedad privada. Así, la idea de libertad ideológica se erige como pantomima y mascarada, la cual pasa a transformarse en libertad sólo para unos pocos privilegiados que imponen esa ideología en aras del beneficio privado. El derecho de libre asociación, el derecho de libre expresión, la potenciación del libre acceso a la cultura o de la libertad de pensamiento ideológico, se deben traducir, en esencia, en el ejercicio de la (simple) voluntad del ciudadano y ciudadana. Voluntad de poder disentir y de elegir qué puede ser lo más beneficioso para el gobierno de 
la colectividad por parte de la propia ciudadanía (demos-pueblo / krátos-gobierno). Todos esos derechos son parte en estos tiempos de esos bienes comunes que hay que defender ante el pensamiento único liberal.

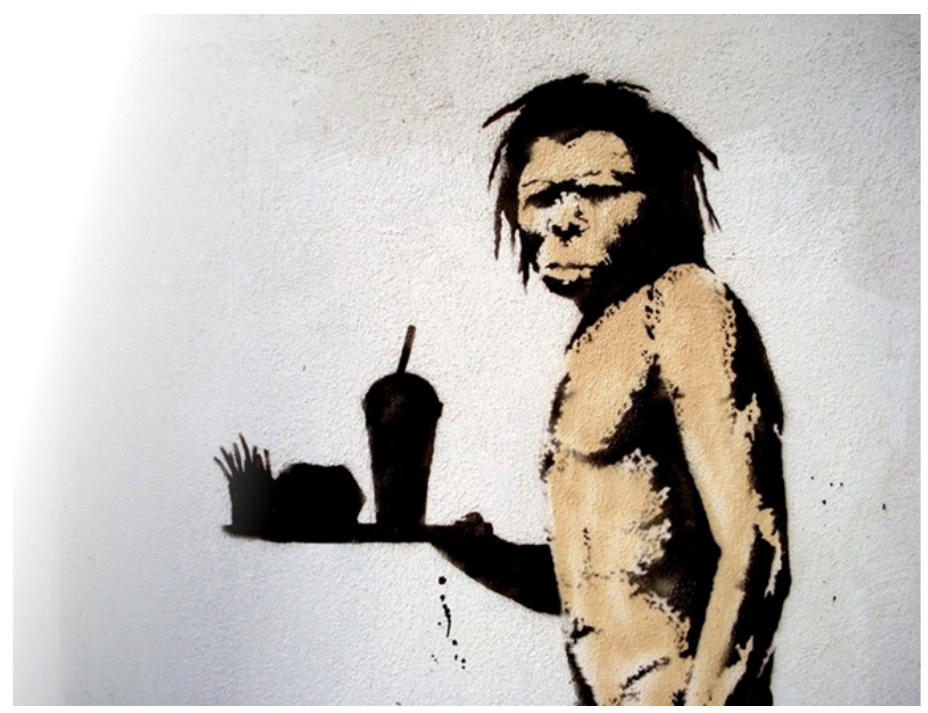

Figura 1. Obra de Banksy fotografía de Stefan Kloo (2008). CC (by).

\subsection{Estimulación cognitiva y aprendizaje}

Si pretendemos desarrollar la noción de bienes de provecho común, se puede concluir que tal concepción, el procomún, es un concepto ancho, plural y elusivo:

- Ancho porque abarca una considerable diversidad de bienes naturales (selvas, biodiversidad, fondos marinos o la Luna), culturales (ciencia, folclore, lengua, semillas, Internet), sociales (agua potable, urbe, democracia, carnaval) y corporales, también llamados de la especie (órganos, genoma, datos clínicos).

- Plural porque son tan múltiples como los muchos modos de existencia que adoptan las comunidades, tanto en el plano local, como en el regional, estatal o internacional, pues no hay comunidad sin un procomún donde asentarse.

- Elusivo porque siendo fundamental para la vida lo tenemos por un hecho dado. Un don que sólo percibimos cuando está amenazado o en peligro de desaparición (Lafuente, 2007, 2). 
Antonio Lafuente concreta la división de procomunes en cuatro entornos:

\begin{tabular}{|c|c|c|c|}
\hline CUERPO & MEDIOAMBIENTE & CIUDAD & DIGITAL \\
\hline $\begin{array}{c}\text { Sensibilidad } \\
\text { Corporalidad }\end{array}$ & $\begin{array}{c}\text { Biosfera } \\
\text { geosfera }\end{array}$ & $\begin{array}{c}\text { doméstico } \\
\text { cultural } \\
\text { urbano }\end{array}$ & $\begin{array}{c}\text { código } \\
\text { estructuras }\end{array}$ \\
\hline
\end{tabular}

(Lafuente, 2007b)

La cultura es un elemento participante y esencial en el desarrollo del procomún en su entorno de ciudad, pero igualmente el procomún cultural tiene relación estrecha con los otros entornos apuntados. Puesto que, en última instancia, las diferentes concepciones (cuerpo, medioambiente, ciudad y digital) son constructos culturales y algunos han influido históricamente en el desarrollo y acceso de la propia cultura. Desde esta perspectiva, hoy, es muy subrayable la labor desempeñada por el procomún digital.

Atendiendo directamente al procomún cultural, Lafuente, especifica los siguientes conceptos como ejemplo de competencias: conocimiento, leyes, historia semillas, paisajes, nombres, símbolos, música, bibliotecas, paz, democracia, sistema financiero internacional, red control de epidemia,... (Lafuente, 2007b).

La organización y producción de los bienes culturales y sus procesos siempre han estado desarrolladas entre el individuo y el colectivo en base a una relación (comunicativa) a tres bandas: creación, difusión, y por último, recepción-consumo.

Dependiendo de cómo ha sido la vinculación entre ellas se fomentaba un modelo u otro de cultura.

Cuando surge el concepto de propiedad intelectual se condiciona el modelo y sus posibles relaciones. Los denominados derechos de autor aparecen en la edad moderna y suponen un control sobre las ideas y la cultura:

"Los derechos de autor nacieron con la invención de la imprenta. En aquellos tiempos, el control de la expresión de las ideas era fácil porque muy pocos podían costearse los instrumentos necesarios para multiplicar las obras. Era a los que podían, a los editores, a quienes iban dirigidas estas leyes. Los ciudadanos no eran los destinatarios de las obligaciones y prohibiciones de los derechos de autor porque la posibilidad de reproducir obras intelectuales no estaba en sus manos" (Bravo, 2005, p.17).

Pero como el mismo autor expone los avances tecnológicos han cambiado todo (Bravo 2005). Un mundo digital encabezado por Internet como símbolo del cambio permanente y la tecnoreproductibilidad ha transformado toda la dinámica del modelo de creación-difusión-consumo.

"La propiedad intelectual se ha volatilizado y se escapa entre los dedos de los que ayer la controlaba. Para frenar esa situación las leyes fingen sólido lo que es gaseoso y convierten en propiedad privada algo que no se puede poseer" (Bravo, 2005, p.17).

No obstante, hay que señalar que la propiedad intelectual surgió como acicate cultural para los propios autores. El Estatuto de la Reina Ana, el cual fue promulgado 
el 10 de abril de 1710, supone el principal precedente en el terreno de los derechos de propiedad intelectual. Como recoge David Bravo, el estatuto "creaba los derechos de autor para "animar a los hombres iluminados a componer y a escribir libros útiles" (Bravo, 2005).

Pero dentro de nuestra realidad nos encontramos con que este 'aliciente' para que el autor cree y comparta su obra ha sido sustituido totalmente por intereses exclusivamente económicos, que bajo la falacia de la "protección de los creadores" ciertas empresas mediadoras han ocupado un espacio antes cedido al derecho legítimo de acceso a la cultura, reconocido constitucionalmente.

En este sentido hay que realizar una reclamación desde los tres niveles comunicativos que forman parte de la esfera cultural: la creación, la difusión y la recepción. Si desde la dimensión creativa y productiva, es decir, los autores y creadores, asumen la cultura como un hecho abierto, necesario y de libre uso, podrán producir un cambio en la figura del receptor facilitando y promocionando igualmente una actitud creativa por parte de éste, provocando conscientemente el proceso colectivo que se le supone a la creación:

"La libertad de uso beneficia al acceso a la cultura y a la cultura misma. (...) Lo que es de todos es aprovechado y disfrutado por todos. Beneficia al desarrollo de la cultura porque, al contrario de lo que durante tantos años se nos ha hecho creer, las musas, sencillamente, no existen. La inspiración no surge de la nada a individuos geniales tocados por la mano de Dios. Son las obras que leemos, las películas que vemos y la música que escuchamos, nuestras verdaderas musas, nuestra vital inspiración y nuestro mejor aprendizaje. La creación es, en realidad, un proceso colectivo. Ideas ajenas que tomamos y a las que imprimimos nuestra nota personal haciéndolas diferentes, historias ya contadas que, mezcladas con otras y con nuestra imaginación, adaptamos y actualizamos, canciones ajenas que durante años se han colado por nuestro oído y que son otras cuando salen por nuestra boca" (Bravo, 2005, p.21).

Así, el procomún recoloca lo que entendemos por actividad creativa, que se traslada de un contexto puramente mercantil a otro más amplio, el de nuestra vida social y nuestra cultura política; en lugar de inmovilizarnos con la dinámica del derecho de propiedad y las transacciones de mercado, el procomún provoca un debate más amplio y más humanista: se pueden renovar las conexiones entre nuestras vidas sociales y los valores democráticos, por un lado, y por otro entre el rendimiento económico, potenciando las virtudes de la transparencia, el acceso universal, la diversidad de los participantes, o una cierta equidad social (Bollier, 2003).

\section{Relaciones del procomún cultural y la educación}

El procomún cultural mantiene un nexo manifiesto con la generación y construcción simbólica, con la elaboración de significados y, en última instancia, con la construcción de conocimiento. Michael Hardt y Antonio Negri reclaman esta nueva manera de entender la noción de los comunes:

"En este terreno deberá emerger una nueva noción de "comunes". Deleuze y Guattari sostienen en ¿Qué es la filosofía? que en la era contemporánea y en el contexto de la 
producción comunicativa e interactiva, la construcción de conceptos no es sólo una operación epistemológica sino igualmente un proyecto ontológico. La construcción de conceptos y los que ellos denominan "nombres comunes" es en verdad una actividad que combina la inteligencia y la acción de la multitud, haciéndolas trabajar juntas. La construcción de conceptos significa hacer existir en la realidad un proyecto que es una comunidad. No hay otro modo de construir conceptos más que trabajar de modo común. Esta comunalidad es, desde la perspectiva de la fenomenología de la producción, desde la perspectiva de la epistemología del concepto, y desde la perspectiva de la práctica, un proyecto en el que la multitud está completamente investida. Lo común es la encarnación, la producción y la liberación de la multitud" (Hardt y Negri, 2000, p.262).

La construcción comunitaria del conocimiento está vinculada directamente a una perspectiva determinada de la comunicación, la cual está asociada a las corrientes críticas de la pedagogía. Tales corrientes pedagógicas potencian la construcción social colaborativa entre los ciudadanos y ciudadanas en aras de una estructura democrática más sólida. Mario Kaplún, en el texto que tendría que ser lectura obligatoria para todo miembro de sistema educativo, deja expuesto:

"Los hombres y los pueblos de hoy se niegan a seguir siendo receptores pasivos y ejecutores de órdenes. Sienten la necesidad y exigen el derecho de participar, de ser actores, protagonistas, en la construcción de la nueva sociedad auténticamente democrática. Así como reclaman justicia, igualdad, el derecho a la salud, el derecho a la educación, etc., reclaman también su derecho a la participación. Y, por tanto, a la comunicación" (Kaplún, 1998, p.63).

La construcción de una cultura entre todos y todas es un compromiso social. Esta actividad colaborativa se logra a través de un modelo comunicativo bidireccional, que se aleja de la concepción cerrada de la emisión y producción de mensajes. Un modelo que se vincula a la noción pedagógica freiriana de dialogicidad y se aleja del pensamiento educativo bancario. Para que exista dialogicidad es necesario compartir la experiencia y vivirla en comunidad. La creación y la creatividad que aquella promueve son de hecho una actividad bidireccional y compartida en la esfera cultural, al igual que como el trabajo realizado en las comunidades científicas es un trabajo recíproco del que todos los científicos y científicas se benefician (Lessig, 2004), produciendo de manera automática un trasvase valioso para el conjunto de la sociedad y su progreso.

\subsection{Educación y cultura digital (como bien público artificial)}

Sara Osuna (2010) se hace eco de las características inferidas por diferentes teóricos de la cultura digital en relación con Internet y el momento actual de la web 2.0:

- La inteligencia colectiva (Pierre Lévy)

- Las Multitudes Inteligentes (Howard Rheingold) y la Sabiduría de las Multitudes (James Surowieck). 
- La Intercreatividad (Tim Berners-Lee).

- La Arquitectura de la Participación (Tim O’Reilly).

Todas las características enunciadas inciden en una concepción colaborativa de la educación y de la construcción social que nos es fácil relacionar con la noción de procomún cultural. Sólo hay que destacar la cita que recoge la autora del ensayista estadounidense Rheingold al referirse a Internet como "ejemplo de bien público artificial con los mejores resultados en los últimos tiempos" (Osuna, 2010, p.140).

No obstante, es la noción de intercreatividad promovida por el creador de la WWW, Berners-Lee, la que se torna más definitoria de la relación entre procomún ( cultural digital) y producción epistemológica, por ende, educativa:

La Intercreatividad "alude a la capacidad de los individuos de expresar y crear sus ideas, conocimientos, etc., de una forma original e inédita a través de los entornos digitales y generando conocimiento colectivo (...) La intercreatividad facilita los mecanismos para que los individuos interactúen creando en comunidad" (p.141).

Estas particularidades intrínsecas al momento digital 2.0 que estamos viviendo pueden ser aprovechadas para desarrollarlas o, por el contrario, obviarlas y negar sus posibilidades. En función de estas opciones se optará por seguir un modelo comunicativo u otro, modelo centrado en la bidireccionalidad y apertura democrática o, por otro lado, una opción unidireccional, cercana a tesis de comunicación dominadora. De igual manera, como subraya Carlos Eduardo Valderrama, hoy "la comunicación se comienza a volver concientemente política" (Valderrama, 2010, p.184): no puede desarrollarse una neutralidad aséptica que evite el compromiso. Queramos o no, la cultura (digital) que se desarrolla en el contexto de Internet mantiene un mensaje implícito que le relaciona con la educación de manera directa:

"Lo comunicacional/educativo ocurre como producción de un nuevo "mundo común". Los medios y las nuevas tecnologías de información y comunicación han producido cambios de tal magnitud que lleva a los más optimistas, como Maffesoli, a considerar que Internet es "la comunión de los santos" posmoderna" (Huergo, 2010, p.78).

\section{Una educación 'move commons' desde la pedagogía crítica, estética y mediática}

\subsection{Perspectivas críticas (mediáticas y estéticas) desde contextos contemporáneos}

Como sugiere Hardt (2011), podemos hacer un gran elenco de las luchas contra la privatización de lo común. Hemos destacado anteriormente que desde la educación se pueden establecer estrategias que promuevan el aprendizaje colaborativo y por el sólo hecho de ponerlas en marcha estaríamos promocionando la idea de una educación compartida como un símbolo y salvaguardia de la comunidad.

Sin embargo, este establecimiento de estrategias de protección de los procomunes debe ser acometido de una manera congruente con un planteamiento plural y colectivo 
que responda con eficiencia a la realidad poliédrica que nos rodea: una realidad dinámica, líquida, en continuo cambio. Esta realidad nos demanda una actitud activa:

"En un mundo volátil como el de la modernidad líquida, en el cual casi ninguna estructura conserva su forma el tiempo suficiente como para garantizar alguna confianza y cristalizarse en una responsabilidad a largo plazo (...), andar es mejor que estar sentado, correr es mejor que andar y hacer surf es mejor que correr" (Bauman, 2007, p.36).

Zygmunt Bauman nos describe un escenario en el que la incertidumbre es la marca de los tiempos (líquidos) en los que nadamos (o al menos nos mantenemos a flote). Nos lo describe, pero debemos ser conscientes que esa actitud activa que la incertidumbre y el dinamismo nos exigen pasa por ser una actitud crítica. Una actitud crítica invita a asumir que la realidad está caracterizada por la celeridad, el desmantelamiento y cambio de las estructuras sociales, pero también nos incita a señalar que esa celeridad y dinamismo incesante tienen unos claros beneficiarios desde el punto de vista económico. Estos beneficiarios tienen los mismos nombres y apellidos que los que finalmente están sustentando las deudocracias actuales y saben que todo se ha convertido en objeto mercante: el saber incluido (como preconizaba Lyotard en 1979). Estos beneficiarios saben que el dinamismo alimenta la especulación y que una falta de control de los tiempos y de la gestión supone una garantía para la realización optima de sus pretensiones. Por este motivo, desde el poder fáctico que encarna el mercado se ataca al posicionamiento ideológico que procura el procomún, ya que este último implica una mirada solidaria: atender lo que nos une, protegerlo y conservarlo para un progreso más humanizado.

De todas maneras, la descripción líquida de Bauman sobre la realidad nos induce a pensar sobre unos retos que la sociedad propone a los sectores educativos, aquellos encargados (oficialmente) de la formación de los individuos como colectivo social. Joe L. Kincheloe desarrolla una síntesis de objetivos que responde a los posibles retos que desde la pedagogía crítica se concretan en:

1. El desarrollo de una imaginación sociocultural. La habilidad de imaginar nuevas formas de autorrealización.

2. La reconstrucción del individuo fuera de los límites del individualismo abstracto.

3. La comprensión del poder y la habilidad para interpretar sus efectos sobre lo social y lo individual.

4. El suministro alternativo de alternativas para la alienación del individuo.

5. El cultivo de una conciencia crítica que es consciente de la construcción social de la subjetividad.

6. La construcción de relaciones democráticas entre individuos que cohesionen la comunidad.

7. La reconceptualización de la razón. Comprender que la existencia relacional no se aplica sólo a los seres humanos, sino también a los conceptos.

8. La producción de habilidades sociales necesarias para activar la participación en una comunidad democrática inclusiva y transformadora.

(Kincheloe, 2008) 
En la medida en que estos retos sean logrados nos alejaremos de una acepción de la educación que ha sido desarrollada en nuestros entornos contemporáneos interpretada bajo la visión economicista vigente, la cual es resumida por McLaren del siguiente modo: "La educación ha sido reducida a un sector de la economía, diseñado para crear ciberciudadanos dentro de una teledemocracia de imágenes rápidas, representaciones y formas de vida" (McLaren, 1999, p.104).

El pensador crítico canadiense aporta una de las claves importantes de contexto para poder encarar cada uno de los retos planteados desde una educación crítica. Esa clave relevante es la configuración de un universo iconográfico e iconológico (por extensión multimedia y digital) que marca profundamente nuestra realidad histórica y política. Desde Debord a Baudrillard alertan de la influencia y el poder de la representación (espectáculo para el primero y simulacro para el segundo) como principio modulador de nuestra cultura y a través de la cual podemos comprender nuestra coyuntura. Roberto Aparici nos orienta en este sentido al plantear que la imagen puede reflejar, reproducir y construir la realidad (Aparici, 2010c), pero "la interpretación de la realidad es siempre modificada por su creador, por la técnica y por el punto de vista del observador" (Aparici, 2010c, p.20). En este sentido, una educación imbricada en este contexto asumirá la complejidad del mismo, en el que la mediación de la imagen produce múltiples posibilidades de lecturas, interpretaciones y mensajes:

"Hay imágenes que tienen un poder simbólico tan grande que se la asocia con su referente más inmediato. La imagen no produce mensajes universales que puedan ser interpretados por todas las sociedades de la misma manera" (Aparici, 2009, p.46).

Así, para atender la ofensiva planteada por Hardt en aras del beneficio común, el planteamiento educativo más congruente supone adentrarnos, comprender y transformar nuestros contextos, al menos, desde una triple vertiente educativa en la que la interrelación y colaboración son necesarias entre ellas:

- Desde la pedagogía crítica: la cual, como hemos apuntado, marca la línea de trabajo común (Freire, 2007; McLaren, 1994; Giroux, 1990).

- Desde la educación mediática: una atención necesaria al alfabetismo digital (Gutiérrez, 2010; Aparici y Osuna, 2010) que "supere la mera destreza mecánica de codificar y descodificar textos en diferentes lenguajes para centrarse en las implicaciones individuales y sociales de su creación, difusión, interpretación, utilización, etc." (Gutiérrez, 2010, p.174).

- Desde una educación visual artística: transformada por el espíritu de los tiempos en educación e-visual, cuya labor se centra en el análisis de la cultura y comunicación visuales, así como en el fomento de la creatividad, sensibilidad y estudios estéticos (Efland, Freedman y Sturh, 2004) necesarios para la composición y generación de una voz (visual) propia. Educación artística que se relaciona directamente con los intereses de la pedagogía crítica cuando 
"localiza la producción artística en su contexto social y examina cómo trabaja de manera intertextual, junto con y sobre otros discursos, pero lo hace con un proyecto político concreto en mente -anti-capitalista, anti-imperialista, anti-sexista y a favor de la lucha emancipatoria y democrática-. (McLaren y Jaramillo, 2011, p.45).

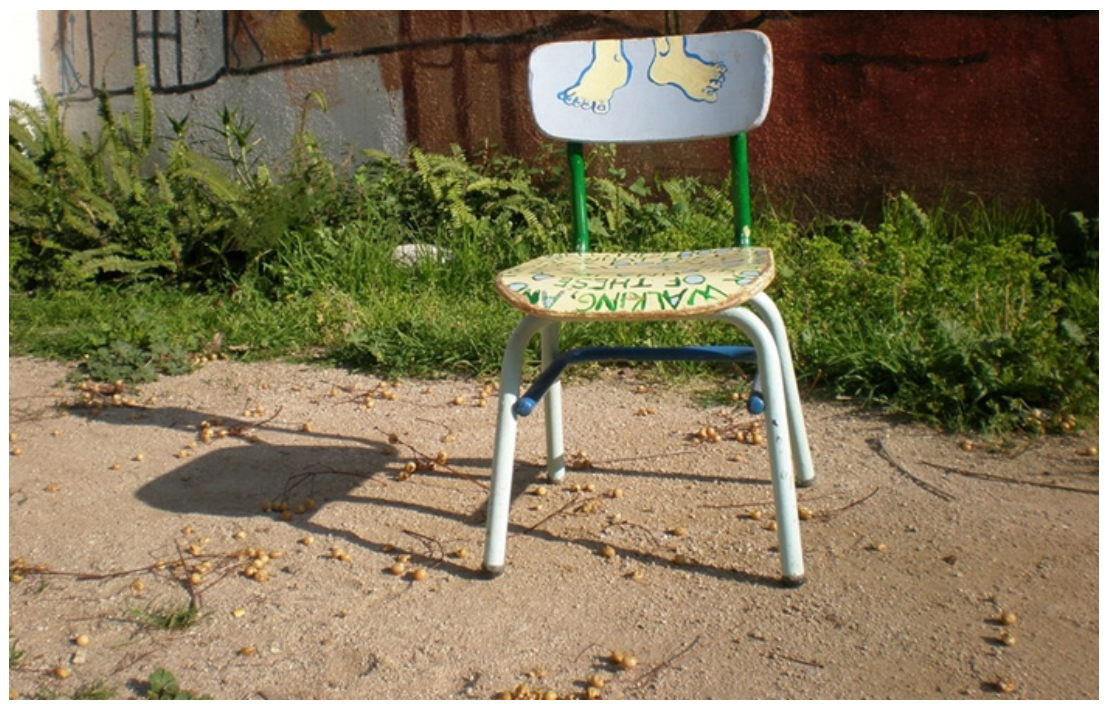

Figura 2. Imagen de Dvdgmz (2009). CC (by).

\subsection{Posibilidades de una Educación Move Commons}

Un tipo de educación construida de manera colaborativa desde plurales puntos de vista (crítico, mediático, e-visual) con objetivos comunes y que, en esencia, está relacionada directamente con la promoción y protección del procomún, podemos identificarla con la siguiente definición: Move Commons (www.movecommons.org).

Existe una asociación sin ánimo de lucro (Asociación Comunes) que, siguiendo la estela de las licencias Creative Commons $(\mathrm{CC})^{2}$-las cuales están pensadas para productos culturales-, ha pensado en facilitar una herramienta para enmarcar iniciativas, acciones o colectivos bajo la fórmula Move Commons (MC): fomentando y e impulsando de manera manifiesta la protección de los comunes. De hecho, se desarrollan unas implicaciones inspiradas en las condiciones $\mathrm{CC}$ pero bajo la nomenclatura $\mathrm{MC}^{3}$.

De todas maneras, aunque así pueda "licenciarse" la actividad educativa colectiva, colaborativa, procuradora del procomún, no significa que si no está de esta 
manera "etiquetada", no exista esa motivación o particularidad. Lo hemos destacado porque con la explicación del concepto y su nombre puede servirnos para mantener una referencia que nos ayude a comprender cuáles son las características de una educación orientada al procomún.

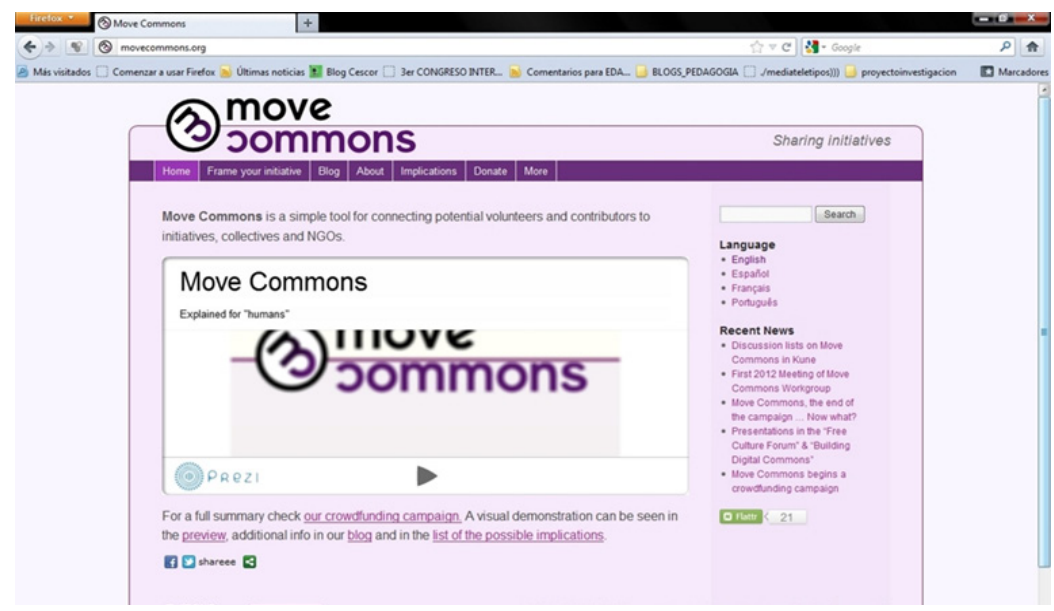

Figura 3. Captura de pantalla de www.movecommons.com.

A continuación se reseñan proyectos y actividades que, desde una mestiza perspectiva mediática y visual, podrían ser ejemplos de una posible Educación Move Commons:

\section{\# Laboratorio del Procomún:}

Como exponen en su web: "El Laboratorio del Procomún tiene como objetivo articular un discurso y una serie de acciones y actividades en torno a este concepto" (MedialabPrado, s.f.,1). Un auténtico laboratorio de aprendizaje colaborativo desarrollado en distintos tipos de actividades (Laboratorio del Procumún, http://medialab-prado.es/ laboratorio_del_procomun).

\section{\# Grupo de trabajo: Cultura(s) de lo común:}

Como parte del Laboratorio del Procomún es destacable, por su clara vinculación educativa, este grupo de trabajo. Articulado a través de taller, wiki y documento libro (Laboratorio del Procomún, http://medialab-prado.es/article/culturas_de_lo_comun).

\section{\#Colaborabora:}

Una plataforma orientada a la acción colaborativa que facilita el aprendizaje (emprendizaje) común que puede calificarse como educolaborativa: "Una iniciativa 
que surge al mezclar una atracción subjetiva y vital por el "procomún"; una inquietud con sentimientos encontrados, ante la falta de iniciativa ciudadana y su promoción institucional bajo el paraguas del "emprendizaje social" (Colaborabora, s.f.,2. http:// www.colaborabora.org).

\section{\#bookcamping:}

Una biblioteca para reseñar, enlazar y descargar contenidos en diversos formatos (textos, audios, videos). De carácter abierto y colaborativo con el compromiso de socializar la lectura y potenciar la cultura compartida (Bookcamping, s.f., http:// bookcamping.cc/).

\section{$\# B C C$ :}

Un proyecto de referencia en la construcción de conocimiento colectivo: El Banco Común de Conocimientos (BCC) surge como un "laboratorio de educación mutua de ciudadano a ciudadano, a raíz de la expansión del software libre, las redes sociales y los sistemas de intercambio de archivos p2p" (BCC, 2006,1. http://www.bancocomun. org). Interesante ilustración audiovisual de un banco común de conocimiento, podemos encontrarla en el documental realizado por el inquieto y creativo grupo de gestión cultural Zemos98, titulado "La Escuela Expandida".

\section{\#Protolab_movil:}

"Es un proyecto de formación y difusión del arte y la cultura electrónica y el conocimiento sustentable a través de la producción de talleres, eventos y tutoriales copyleft" (Protolab_movil, s.f., 1.http://protolabmovil.cc/).

\section{\#Twittanálisis La condición postmoderna:}

Como práctica puntual, que participa de los principios de esta posible Educación Move Commons, se promocionó esta actividad educativa y de carácter experimental dentro de un marco universitario. Utilizando la red social Twitter y con motivo del análisis de la obra de Jean-François Lyotard se puso en marcha esta tarea que aunaba intereses de estudiantes de la Universidad Nacional de Educación a Distancia (del master Educación y Comunicación en la Red: de la sociedad del conocimiento a la sociedad de la Información) y de la Universidad de Sevilla (de la facultad de Bellas Artes). El objetivo se centraba en hacer un análisis colectivo (generar un debate plural y construir conocimiento entre todos y todas) promocionando la síntesis y la comunicación, sobre la obra de Jean-François Lyotard. Un texto de gran relevancia para aproximarnos a la comprensión de nuestro contexto contemporáneo y sus relaciones con el saber y su legitimación (http://www.carlosescano.com/cpostmoderna/).

\section{Conclusiones (o 'sinclusiones')}

Cerrar el texto de este artículo con un apartado de conclusiones sería algo incongruente puesto que estaría planteado desde un punto de vista unidireccional. Sería más interesante usar el término de sinclusiones. Creo que se ajusta mejor a la idea de un trabajo de referencias colaborativas y siempre abiertas y en construcción. 
Antonio Negri y Michael Hardt sentencian de manera grave que "no pretendemos llorar sobre la destrucción y expropiación que el capitalismo opera continuamente en todo el mundo, aunque resistir su fuerza (y en particular resistir la expropiación del Estado de Bienestar) sea por cierto una tarea importante y eminentemente ética" (2000, p.261) Este leitmotiv subyace, en esencia, en el trabajo en torno al procomún. No cabe duda de que es un trabajo ideológico y educativo. Aunque estos funcionan como sinónimos. Un trabajo que se manifiesta como necesario en tiempos como los actuales donde la educación está siendo sometida a embestidas neoliberales que ponen en solfa tanto la igualdad distributiva de oportunidades en la educación como la igualdad social de las mismas. Es necesario defender una educación común y una cultura común en aras de ofertar una justicia social. Decía François Dubet, en relación a su Francia natal, que los padres fundadores de la escuela republicana definieron la cultura común como "todo lo que no está permitido ignorar" (2005). Existe una obligación ética que nos empuja a impedir que haya una ignorancia de lo comunitario, de los lazos culturales y educativos que nos unen. Por otro lado, este compromiso es adquirido por parte de la ciudadanía: establecer esos nexos comunes desde la educación. Una educación que, ubicada en la actualidad interconectada y plural, debe volverse multifacética e interdisciplinar, educación que debe desarrollarse desde diferentes flancos (oficiales y no formales, multimediáticos y e-visuales), pero siempre con la perspectiva crítica obligatoria para convertirse en un agente transformador y, según el pensamiento de Paulo Freire, reconstructora del mundo.

"Poblad con igualdad el territorio, estableced idénticos derechos, llevad por todas partes la abundancia y la vida, y el Estado llegará a ser el más fuerte a la vez que el mejor gobernado que sea posible" (Rousseau, 2004, p.158).

\section{Referencias}

\section{Documentos monográficos y artículos}

Aparici, R. (coord.) (2010). Conectados en el ciberespacio. Madrid: UNED. Aparici, R. (coord.) (2010b). Educomunicación: más allá del 2.0. Barcelona. Gedisa. Aparici, R. (coord.) (2010c). La construcción de la realidad en los medios de comunicación. Madrid: UNED.

Aparici, R., García, A., Fernández, J. y Osuna, S. (2009): La imagen. Análisis y representación de la realidad. Barcelona: Gedisa.

Aparici, R. y Osuna, S. (2010). Educomunicación y cultura digital (pp.307-318). En Aparici, R. (coord.) Educomunicación: más allá del 2.0. Barcelona. Gedisa.

Aristóteles (s.f.). Politica. Disponible en: http://usuarios.multimania.es/politicasne/ documentos/politica.pdf

Benkler, Y. (2003). La economía política del procomún. Disponible en: http:// biblioweb.sindominio.net/telematica/yochai.pdf

Bauman, Z. (2007). Los retos de la educación en la modernidad líquida. Barcelona: Gedisa. 
Bollier, D. (2003). El redescubrimiento del procomún. Disponible en: http:// biblioweb.sindominio.net/telematica/bollier.pdf

Bravo, D. (2005). Copia este libro. Madrid: Dmem.

Debord, G. (2008). La sociedad del espectáculo. Valencia: Pre-textos.

Dubet, F. (2005). La escuela de las oportunidades ¿Qué es una escuela justa? Barcelona: Gedisa.

Efland, A.; Freedman, K. y Sturh, P. (2004). Educación en el arte posmoderno. Barcelona: Paidós.

Freire, P. (2007). Pedagogía del oprimido (17 reimpresión). Madrid: Siglo XXI Editores.

Giroux, H. (1990). Los profesores como intelectuales: hacia una pedagogía crítica del aprendizaje. Barcelona: Paidós.

Gutiérrez, A. (2010). Creación multimedia y alfabetización en la era digital (pp. 171-186). En Aparici, R. (coord.). Educomunicación: más allá del 2.0. Barcelona. Gedisa.

Huergo, J.A. (2010). Una guía de comunicación/educación, por las diagonales de la cultura y la política (pp.65-104). En Aparici, R. (coord.). Educomunicación: más allá del 2.0. Barcelona. Gedisa.

Kincheloe, J.L. (2008). La pedagogía crítica en el sigo XXI: evolucionar para sobrevivir (pp. 25-69). En McLaren, P. y Kincheloe, J.L. Pedagogía Crítica. De qué hablamos, dónde estamos. Barcelona: Graó.

Kaplún, M. (1998). Una pedagogía de la comunicación. Madrid: Ediciones de la Torre.

Lafuente A. (2007). Qué es el Procomún. Disponible en: http://medialab-prado.es/ article/video que es el procomunLafuente

Lafuente A. (2007b). Los cuatro entornos del procomún. Archipiélago. Cuadernos de Crítica de la Cultura, 77-78, 15-22.

Lessig, L. (2004). Cultura ibre. Disponible en: http://cyber.law.harvard.edu/blogs/ gems/ion/Culturalibre.pdf

Lyotard, J-F. (1998). La condición postmoderna (6 $6^{\mathrm{a}}$ Ed.). Madrid: Cátedra.

Martínez, J. A. (2011). El poder, el bien común y los intereses individuales y sociales, en Contribuciones a las Ciencias Sociales. Disponible en: http://www.eumed.net/ $\mathrm{rev} / \mathrm{cccss} / 12 / \mathrm{jamg} . \mathrm{htm}$

McLaren, P. (1994). La vida en las escuelas: Una introducción a la pedagogía crítica en los fundamentos de la educación. México: Siglo XXI Editores.

McLaren, P. (1999). Pedagogía revolucionaria en tiempos posrevolucionarios: repensar a economía política de a educación crítica (pp.101-120). En Imbernón, F. (Coord.). La educación en el siglo XXI. Los retos del futuro inmediato. Barceona: Graó.

McLaren, P. y Kincheloe, J.L. (2008). Pedagogía Crítica. De qué hablamos, dónde estamos. Barceona: Graó.

McLaren, P. y Jaramillo, N. (2011). Las artes, la estética y la pedagogía crítica (pp.3760). En Escaño, C. y Gutiérrez, R. Actas 3er Congreso Internacional de Educación Artística y Visual. Málaga: Universidad de Málaga (SPICUM)

Negri y Hardt (2000): Imperio. Cambridge: Harvard University Press. 
Osuna (2010). Interactuantes e interactuados en la Web 2.0. En Aparici, R. (coord.). Conectados en el ciberespacio ( pp.135-150). Madrid: UNED.

Rousseau, J-C. (2007). El contrato social (19a Ed.) Madrid: Edaf.

Valderrama, C.E. (2010). Movimientos sociales: TIC y prácticas políticas. En Aparici, R. (coord.). Conectados en el ciberespacio (pp.175-188). Madrid: UNED.

\section{Recursos electrónicos}

http://www.bancocomun.org

http://bookcamping.cc/

http://www.carlosescano.com/cpostmoderna/

http://www.colaborabora.org

http://www.creativecommons.es

http://www.goteo.org

http://medialab-prado.es/laboratorio_del_procomun

http://medialab-prado.es/article/culturas_de_lo_comun

http://www.movecommons.org

http://protolabmovil.cc/

http://www.zemos98.org

\section{Notas}

1. La película Deudocracia (2010) es el ejemplo ilustrativo de esta circunstancia. Un documental realizado por Katerina Kitidi y Ari Hatzistefanou.

2. Licencias que permiten un uso abierto de las obras y están relacionadas con las siguientes condiciones de uso (información extraída de Creative Commons: http:// es.creativecommons.org/licencia/ ) :

- Reconocimiento (Attribution): En cualquier explotación de la obra autorizada por la licencia hará falta reconocer la autoría.

- No Comercial (Non commercial): La explotación de la obra queda limitada a usos no comerciales.

- Sin obras derivadas (No Derivate Works): La autorización para explotar la obra no incluye la transformación para crear una obra derivada.

- Compartir Igual (Share alike): La explotación autorizada incluye la creación de obras derivadas siempre que mantengan la misma licencia al ser divulgadas". (Creative Commons, 2011)

3. La expansión del uso de estas "etiquetas" provocaría la aparición de dinámicas interesantes. Los creadores de la iniciativa explican que (información extraída de Move Commons: http://movecommons.org/es/implications/): [En relación a las dinámicas]: "unas serán inesperadas, pero hay otras que esperamos que sucedan. Hemos construido la siguiente lista de implicaciones deseadas que cabría esperar:

Implicaciones de las cuatro preguntas: 
Sin ánimo de lucro / Ánimo de lucro: MC anima a las personas que quieren involucrarse (pero no saben cómo) y facilita su participación, puesto que pueden fácilmente encontrar donde ayudar de acuerdo con sus intereses y habilidades.

Reproducible / Exclusivo: MC promueve la "buena práctica" en el activismo, de la misma forma en que el método científico fomenta la "buena ciencia": el principio de reproducibilidad es básico en la ciencia. Aun así, hay iniciativas que por ciertas razones prefieran mantener su trabajo protegido.

Reforzando los Comunes: MC impulsa la protección de los Comunes, y la construcción de iniciativas que siguen su línea en las soluciones para nuestros problemas sociales, en cada campo de acción.

Horizontal / Jerárquica: MC promueve iniciativas horizontales en línea de acuerdo con los nuevos paradigmas de organización que están emergiendo actualmente como una alternativa a las burocráticas jerarquías piramidales. Debido a que éste es un periodo de transición, muchos colectivos aún prefieren mantener ciertos niveles de representación dentro de su estructura interna. 